\title{
Turizm ve Ağırlama Sektöründe Çalışanların Kurumsal Sosyal Sorumluluk Faaliyetlerine Yönelik Tepkileri Üzerine Bibliyometrik Bir Çalışma
}

\section{A Bibliometric Study on Employees' Reactions to Corporate Social Responsibility Practices in Tourism and Hospitality Industry}

\author{
Dr. Öğr. Üyesi Erhan BOĞAN \\ Adıyaman Üniversitesi \\ Turizm Fakültesi \\ E-posta: ebogan@adiyaman.edu.tr
}

\section{Öz}

$\mathrm{Bu}$ çalışma, turizm ve ağırlama sektöründe çalışanların kurumsal sosyal sorumluluk faaliyetlerine yönelik verdikleri tepkileri araştıran makaleleri kapsayan bibliyometrik ilk çalışmadır. Çalışmada, 2019 yılına kadar turizm ve ağırlama alanında yer alan akademik dergilerde İngilizce yayınlanan makaleler incelenmiştir. Yapılan analiz sonucunda, çalışmaların büyük bir kısmının International Journal of Hospitality Management ve International Journal of Contemporary Hospitality Management dergilerinde yayınlandığı belirlenmiştir. Çalışmaların çoğunlukla Asya ülkelerinde gerçekleştirildiği; 2019 yılının en fazla yayın yapılan yıl olduğu; sosyal kimlik teorisi ve sosyal mübadele teorisinin en fazla yararlanılan teoriler olduğu; kurumsal sosyal sorumluluğun duygusal bağlılık, örgütsel özdeşleşme ve iş tatmini üzerine etkisinin en fazla çalışılan konular olduğu belirlenmiştir. Elde edilen bulgular doğrultusunda, araştırmacılara birtakım tavsiyelerde bulunulmuştur.

Anahtar Kelimeler: Kurumsal Sosyal Sorumluluk, Çalışanların Tutum ve Davranışları, Turizm ve Ağırlama Dergileri.

\begin{abstract}
This is the first bibliometric study that investigates employees' reactions to corporate social responsibility practices in tourism and hospitality industry. In this study, articles published in academic journals until 2019 were examined. As a result of the analysis, it was determined that most of the studies were published in International Journal of Hospitality Management and International Journal of Contemporary Hospitality Management. It was indicated that the studies were mostly carried out in Asian countries; the highest number of articles were published in 2019; social identity theory and social exchange theory are the most widely used theories in articles; the effect of corporate social responsibility on affective commitment, organizational identification and job satisfaction are the most studied topics. In line with the findings, some recommendations were provided to the researchers.
\end{abstract}

Key Words: Corporate Social Responsibility, Employees' Attitude and Behaviors, Tourism and Hospitality Journals. 


\section{Giriş}

Avrupa Birliği Komisyonu (2001:4) tarafından "işletmelerin gönüllülük esasına bağlı olarak paydaşları ile etkileşimlerinde ve ticari faaliyetlerinde çevresel ve sosyal sorunları bütünlemesi" olarak tanımlanan kurumsal sosyal sorumluluk (KSS) kavramına, sektör temsilcilerinin ve araştırmacıların ilgisi giderek artmaktadır. İşletmeler, yerel halka istihdam sağlama, yerel tedarikçilerle çalışma gibi ekonomik; enerji-su tasarrufu, geri dönüşüm, doğal çevreyi koruma ve geliştirme gibi çevresel; okul, hastane vb. yapımına finansal destek sağlama, sosyo-kültürel organizasyonlara sponsorluk yapma ve yerel kültürün korunmasına katkı sağlama gibi sosyal alanda sorumlu girişimler yürütmektedir (Gursoy ve diğ., 2019). Bu girişimlerle işletmeler, sürdürülebilir kalkınma ilkelerinin hayata geçmesinde aktif rol üstlenmektedir. Son yıllarda, KSS uygulamalarına önderlik eden büyük ve lüks turizm işletmelerinin yanı sıra bu kavramın artan önemine bağlı olarak küçük-orta ölçekli işletmeler ve aile işletmeleri de faaliyet gösterdikleri bölgede insanların yaşam kalitesini arttıracak sorumlu faaliyetler yürütmektedirler (Thomas ve diğ., 2011). Bir diğer ifadeyle, KSS faaliyetleri ölçeğine bakılmaksızın artık birçok işletmenin stratejik planlamasında kendisine yer bulmaktadır.

KSS kavramının turizm sektöründe faaliyet gösteren işletmeler için stratejik önemini ortaya koyan çalışmalar ilk dönemlerde işletmenin çoğunlukla finansal performansı ile ilişkilendirilmiştir (Rodríguez ve Cruz, 2007; Lee ve Park, 2009). Bu faaliyetlerin işletme finansal performansına olumlu katkılar sağladığı belirlenmiştir. Finansal performansın yanında KSS faaliyetleri işletmelerin önemli paydaşlarından biri olan müşterilerin işletmeye yönelik olumlu tutum ve davranışlar sergilemesine katkı sağladığına dair turizm literatüründe çok sayıda çalışma mevcuttur (García de Leaniz ve Rodríguez Del Bosque Rodríguez, 2015; Gürlek ve diğ., 2017; Kang ve Namkung, 2018). Son yıllarda paydaş grubu içerisinde çalışanların KSS faaliyetlerine verdikleri tepkileri araştıran çalışma sayısı da giderek artmaktadır. Song ve arkadaşlarına (2015) göre, ağırlama sektöründe KSS uygulamalarının çalışanların tutum ve davranışları üzerine etkisinin araştırılması son derece önemlidir. Çünkü, bu sektörde çalışanlar müşterilerle doğrudan etkileşim halindedir. Çalışanlar, pazarda meydana gelen değişimler ve tüketici tercihleri hakkında bilgi edinirler ve böylece müşteri tatmininin nasıl sağlanacağı hususunda öneriler geliştirip, uygularlar (Korschun ve diğ., 2014). Aynı zamanda, turistik ürünün soyut yapısından dolayı müşterilere karşı gösterilen tutum ve davranışlar, müşteri deneyiminin şekillenmesinde ve sonuç olarak müşteri tatmini ve sadakatinde büyük öneme sahiptir (Ko ve diğ., 2019).

Artan araştırmacı ilgisine rağmen, turizm ve ağırlama sektöründe çalışanların KSS faaliyetlerine verdikleri tepkileri içeren çalışmalara dair durum analizinin yapılmadığı belirlenmiştir. Dolayısıyla mevcut çalışma literatürde yer alan bu boşluğu doldurmayı amaçlamaktadır. Konuya dair yapılan çalışmaların yıllara-ülkelere-dergilerealt sektörlere dağılımı, en çok işlenen konular, en çok faydalanılan teoriler ve çalışmalardaki yazar sayısı mevcut durumun belirlenmesi ve araştırmacılara öneriler geliştirilmesi açısından önem arz edecektir. Çalışmanın amacına ulaşması için konuya dair 2019 yılına kadar yapılmış nicel çalışmalar bibliyometrik analiz tekniği ile incelenmiştir.

$\mathrm{Bu}$ bağlamda, kavramsal çerçeve kapsamında KSS kavramı, ağırlama sektöründe KSS uygulamaları ve bu sektörde çalışanların kurumsal sosyal sorumluluk faaliyetlerine yönelik verdikleri tepkileri içeren bir literatür incelemesi yapılacaktır. Çalışmanın yöntem kısmında, bibliyometrik analiz hakkında bilgi verildikten sonra dergilerin nasıl seçildiği açıklanacaktır. Ardından bulgular, ilgili literatürdeki çalışmalarla 
birlikte tartışılacaktır. Son olarak çalışmanın sonuçları ve kısıtlarına yer verilip araştırmacılara konu tavsiyelerinde bulunulacaktır.

\section{Kavramsal Çerçeve}

\subsection{Kurumsal Sosyal Sorumluluk}

Modern anlamda KSS kavramının geçmişi 1950'li yıllara dayanmaktadır. Carroll (1989), 1950 'li yılları sosyal sorumluluk kavramının kabul gördüğü ve kavramın içerik anlamında genişlediği yıllar olarak kabul etmektedir. O dönemlerde Bowen (1953) sosyal sorumluluğu, gelecekte işletmelere rehberlik edecek, tüm iş adamlarının karşılaşacağı önemli bir realite olarak nitelendirmektedir. Dönemdeki ileri görüşlülüğü, bilim dünyasını farklı bir kavram ile tanıştırması ve iş adamlarına farklı bir vizyon kazandırması nedeniyle Carroll (1999: 270) Bowen'i "kurumsal sosyal sorumluluğun babası" olarak nitelendirmiştir. Bowen (1953: 6) KSS kavramını; "işletmelerin hem kendi amaçlarına hem de toplumsal değerler ve beklentilere uygun politikalar belirleme, uygulama, karar verme ve faaliyetleri yerine getirmeyle toplumun yaşamını iyileştirmeye ilişkin yükümlülüklerin bir bütünü" olarak tanımlamaktadır.

KSS kavramının gelişimine önemli katkılardan birini de Archie B. Carroll sağlamıştır. Carroll (1979) işletmelerin KSS alanlarını dört basamaktan oluşan bir piramitte ele almıştır. Bu piramidin basamaklarını alttan yukarıya doğru sırasıyla ekonomik, yasal, etik ve gönüllü sorumluluk oluşturmaktadır. Ekonomik sorumluluk, işletmelerin mal-hizmet üretip satması ve kar elde etmesi sorumluluğudur. Yasal sorumluluk, işletmenin faaliyetlerini gerçekleştirirken yasal düzenlemelere riayet etmesi sorumluluğudur. Etik sorumluluk, yasal düzenlemelerde yer almayan ancak toplum tarafından genel kabul görmüş normlara ve değerlere uygun hareket edilmesi sorumluluğudur. Son olarak gönüllü sorumluluk ise, işletmelerin toplumun yaşam kalitesini arttırma amacıyla yürütülen hayırseverlik faaliyetlerini kapsamaktadır (Carroll, 1991). Sosyal sorumluluk alanlarını içeren Carroll'un bu modeli, günümüzde KSS kavramının ölçümünde kullanılan ve en fazla kabul gören yöntemdir (Lee ve diğ., 2012; Fu ve diğ., 2014a; Wang, 2014; Song ve diğ., 2015; Kim ve diğ., 2016; Kim ve diğ., 2017).

Günümüzde işletmelerin çevresinde meydana getirdiği olumsuz etki; medya, sivil toplum kuruluşları ve devlet tarafından sıkça dile getirilmektedir. Bu baskı karşısında bazı büyük işletmeler yayınladıkları sosyal sorumluluk ya da çevre etki değerlendirmeleri raporları ile bu baskıya karşı imaj zedelenmesini önleme, var olan imajlarını koruma hatta geliştirme çabasındadır. Bu durum, işletmeleri stratejik raporlarında ve politikalarında kurumsal sosyal sorumluluk faaliyetlerine de yer vermek zorunda bırakmıştır (Porter ve Kramer, 2006). Konu turizm ve ağırlama sektörüne geldiğinde, turistlerin çevresel ve sosyal anlamda farkındalık düzeylerinin artması (Jiang ve Gao, 2019), kalifiye işgücünün sorumlu girişimler beklemesi (Boğan ve Dedeoğlu, 2019b) ve artan rekabet dikkate alındığında, ölçeğine bakılmaksızın sektörün farklı alt dallarında faaliyetlerini sürdüren işletmeler, sosyal ve çevresel anlamda sergiledikleri sorumlu faaliyetleri paydaşlarına duyurmaktadır. Böylece işletmeler, toplum, müşteriler ve işgücünün beklentilerine karşılık vererek hem meşruiyet kazanma hem de rekabet üstünlüğü elde etmeyi amaçlamaktadır (Li ve diğ., 2015).

KSS faaliyetlerinin stratejik bir gereklilik olarak kabul edilmesinin ardından bir diğer önemli konu kurumsal sosyal sorumluluğun nasıl ölçüleceğidir. Meta bir yapı olan KSS kavramı çok boyutlu ölçüldüğü gibi tek bir boyuta indirgenerek de ölçülmüştür (Song ve diğ., 2015; Luu, 2017; Park, Lee ve Kim, 2018; Şentürk ve diğ., 2019; He ve diğ., 
2019; Jia ve diğ., 2019; Boğan ve Dedeoğlu, 2019b; Su ve Swanson, 2019). İlk dönemlerde çoğunlukla Carroll'un KSS piramidinin basamaklarını esas alarak ölçümler yapılmıştır (Lee ve diğ., 2012; Wang, 2014; Fu ve diğ., 2014a; Song ve diğ., 2015; Kim ve diğ., 2016; Kim ve diğ., 2017). Daha sonraları araştırmacılar paydaş teorisinden faydalanarak çalışanlar, müşteriler, devlet, doğal çevre ve toplum gibi paydaşlara karşı sosyal sorumluluk gibi ölçekler geliştirmiştir (Youn ve diğ., 2018; He ve diğ., 2019; Boğan ve Dedeoğlu, 2019a; 2019b; Gürlek ve Tuna, 2019; Ko ve diğ., 2019). Konuya dair geliştirilen bir diğer ölçüm aracı, sürdürülebilir kalkınmanın ekonomik, sosyal ve çevresel boyutlarını içermektedir (Cowper-Smith ve de Grosbois, 2011; Gursoy ve diğ., 2019). Son olarak, son birkaç yıldır turizm ve ağırlama sektörünün kendisine has özelliklerine vurgu yapılarak farklı ölçüm araçları geliştirilmiştir (Fatma ve diğ., 2016; Luo, 2018; Ko ve diğ., 2019). Bu ölçüm araçlarıyla, KSS ve finansal performans ilişkisinin yanı sıra müşterilerin, çalışanların, potansiyel işgücünün ve toplumun işletmelere yönelik KSS algılamaları ölçülmektedir.

\subsection{Turizm Sektöründe KSS Uygulamaları}

Ağırlama endüstrisinde ilk dönemlerde KSS kavramı çoğunlukla çevresel uygulamalarla eş değer görülmüştür (Coles ve diğ., 2013). İşletmelerin enerji-su tasarrufu, geri dönüşüm vb. doğal çevreyi koruma faaliyetleri sosyal sorumluluk kapsamında ele alınmıştır. Ancak son yıllarda, KSS kavramı içerisinde çevresel uygulamalara ek olarak paydaşların yaşam kalitesini artırıcı ekonomik ve sosyo-kültürel girişimlerin yer aldığı çalışmalar da yapılmaktadır. Günümüzde birçok ulusal ve uluslararası işletme topluma fayda sağlayacak girişimlerde bulunarak, paydaşlarına bu girişimleri farklı kanallarla iletmektedir. Örneğin; Hilton otelleri yaptıkları sosyal sorumluluk faaliyetlerini ayrı bir web sayfası oluşturarak paydaşlarına duyurmakta ve her yıl oluşturdukları raporlarla paydaşlarını bilgilendirmektedir. Bunun yanında dünyanın önde gelen kafe işletmelerinden biri olan Starbucks kurumsal web sayfasında 'sosyal etki' başlığı altında gerçekleştirdikleri sorumlu girişimleri paydaşlarına iletmektedir. Bu sorumlu girişimler, kamuoyu nezdinde işletmelerin imajlarını güçlendirerek paydaşlarda olumlu izlenimler oluşturmaktadır. Bu girişimler vasıtasıyla müşteriler, toplum, mevcut çalışanlar ve potansiyel işgücü sorumlu işletmelere karşı olumlu tutum ve davranışlar sergilemektedir.

García de Leaniz ve Rodríguez Del Bosque Rodríguez (2015) İspanya'da otel müşterilerinin KSS algısının müşteri güveni, müşteri bağııı̆̆ı ve müşterilerin işletme ile özdeşleşmesi üzerine olumlu etki oluşturduğunu tespit etmiştir. Gürlek ve arkadaşları (2017) İstanbul'da beş yıldızı otel müşterilerinin KSS algısının müşteri sadakati üzerine etkisinde kurumsal imaj algısının aracılık rolü üstlendiğini belirlemiştir. Yine müşteriler bağlamında Kang ve Namkung (2018) Starbucks müşterilerinin ekonomik, yasal, etik ve gönüllü sorumluluk algılamalarının marka farkındalığı, marka imajı, algılanan kalite ve marka sadakati boyutlarından oluşan marka denkliği üzerine etkisini araştırmıştır. Yapılan analizler sonucunda müşterilerin ekonomik, yasal ve etik sorumluluk algısının marka denkliği üzerine pozitif bir etki oluşturduğu görülmüştür.

Paydaş grubu içerisinde potansiyel işgücünün de KSS faaliyetlerini gerçekleştiren işletmelere karşı olumlu tutum ve davranışlar sergilediği belirlenmiştir. Bu kapsamda, Boğan ve Dedeoğlu (2019b) Türkiye'de turizm programlarında lisans düzeyinde eğitim alan öğrencilerin çalıştıkları otel işletmelerine yönelik KSS algısının sektöre olan bağlılık ve oteli başkalarına tavsiye etme tutumları üzerine etkisini araştırmışlardır. Yapılan analizler sonucunda, öğrencilerin çevreye yönelik sorumluluk algısının sektöre olan bağlılık ve tavsiye etme tutumları üzerine pozitif bir etki oluşturduğu belirlenmiştir. Yılmazdoğan ve arkadaşları (2014) Eskişehir'de eğitim gören turizm öğrencilerinin KSS algısının sektörde çalışma niyeti üzerine etkisini araştırmışlardır. Çalışmada KSS 
kavramı ekonomik, yasal, etik ve gönüllü sorumluluk boyutlarıyla ölçülmüştür. Yapılan analiz sonucunda, öğrencilerin KSS algısının sektörde çalışma niyeti üzerine pozitif bir etki oluşturduğu belirlenmiştir.

KSS uygulamalarına verilen tepkiler kapsamında araştırılan bir diğer paydaş grubu yerel halktır. Su ve arkadaşları (2018) Çin'de yerel halkın destinasyon seviyesinde sosyal sorumluluk algısının turizmin olumlu etkisine yönelik algı, turizme destek ve yaşam kalitesi üzerine pozitif bir etki oluşturduğunu belirlemiştir. Gursoy ve arkadaşları (2019) Alanya'da yerel halkın otel işletmelerine yönelik KSS algısının toplumun tatmini, bölgeye olan bağlılığı ve turizme olan desteği üzerine etkisini araştırmışlardır. Yerel halkın ekonomik ve çevresel sorumluluk algısının turizme destek; ekonomik, sosyal ve çevresel sorumluluk algısının tatmin üzerine pozitif bir etki oluşturmuştur. Lee ve arkadaşları (2018) ise, kumarhane işletmelerinin KSS faaliyetlerinin yerel halkın yaşam kalitesi, algılanan fayda ve turizme destek üzerine etkisini araştırmışlardır. Güney Kore'de yaşayan yerel halktan toplanan verilerle yapılan analizler sonucunda, halkın KSS algısının yaşam kalitesi, turizme destek ve algılanan fayda üzerine pozitif bir etki oluşturduğu belirlenmiştir.

\section{3. Çalışanların KSS Faaliyetlerine Verdikleri Geri Dönüşler}

Paydaş grubu içerisinde çalışanlar, hem ne tür KSS faaliyetinin gerçekleştirilmesi gerektiği konusunda fikirler sunmada, hem de bu faaliyetlerin başarılı bir şekilde uygulanmasında kritik bir öneme sahiptir. Bunun yanında bu sektörde çalışanlar müşterilerle doğrudan etkileşim halindedir. Çalışanlar, pazarda meydana gelen değişimler ve tüketici tercihleri hakkında bilgi edinirler ve böylece müşteri tatmininin nasıl sağlanacağı hususunda öneriler geliştirip, uygularlar (Korschun ve diğ., 2014). Aynı zamanda, turistik ürünün soyut yapısından dolayı müşterilere karşı gösterilen tutum ve davranışlar, müşteri deneyiminin şekillenmesinde ve sonuç olarak müşteri tatmini ve sadakatinde büyük öneme sahiptir (Ko ve diğ., 2019). Bu noktada, çalışanların KSS faaliyetlerini nasıl algıladıkları ve bu faaliyetlerin çalışanların tutum ve davranışlarına nasıl yansıdığının araştırılması gerekmektedir (Song ve diğ., 2015).

KSS faaliyetlerinin finansal performans ve müşterilerin işletmeye dönük tutum ve davranışlar üzerine etkisinden sonra en fazla araştırılan konuların başında, çalışanların bu faaliyetleri nasıl algıladığı ve bu faaliyetlerin tutum ve davranışlarına nasıl bir etki oluşturduğu gelmektedir. Yapılan araştırmalar, çalışanların KSS algısının örgütsel bağlılık (Fu ve diğ., 2014a; Song ve diğ., 2015; Kim ve diğ., 2016), örgütsel özdeşleşme (Park ve Levy, 2014; Fu ve diğ., 2014a; Boğan ve diğ., 2018a; He ve diğ., 2019; Su ve Swanson, 2019; Gürlek ve Tuna, 2019), örgütsel vatandaşlık davranışı (Fu ve diğ., 2014a; 2014b; Raub ve Blunschi, 2014; Kim ve diğ., 2017; He ve diğ., 2019), örgütsel güven (Lee ve diğ., 2012; 2013; Jia ve diğ., 2019; Boğan ve Dedeoğlu, 2019a; Su ve Swanson, 2019), bilgi paylaşımı (Jia ve diğ., 2019), çevresel anlamda örgütsel vatandaşlık davranışı (Luu, 2017; Su ve Swanson, 2019), işe adanmışlık (Lee ve diğ., 2014; Zientara ve diğ., 2015; Park ve diğ., 2018; Gürlek ve Tuna, 2019), işte kalma niyeti (Park ve diğ., 2018), işten ayrılma niyeti (Lee ve diğ., 2014; Kim ve diğ., 2016), yapılan işin anlamlılığı (Raub ve Blunschi, 2014; Supanti ve Butcher, 2019), yenilikçi davranış (Park ve diğ., 2018), duygusal bağlılık (Fu ve diğ., 2014b; Wong ve Gao, 2014; Wang, 2014; Zientara ve diğ., 2015; Kim ve diğ., 2017; Youn ve diğ., 2018), örgütsel inovasyon (Wang, 2014), iş tatmini (Lee ve diğ., 2012; Raub ve Blunschi, 2014; Zientara ve diğ., 2015; Youn ve diğ., 2018; Boğan ve diğ., 2018a; Appiah, 2019), duygusal tükenmişlik (Raub ve Blunschi, 2014), içsel motivasyon (Nazir ve Islam, 2019), müşterilere dönük örgütsel vatandaşlık davranışı (Bavik, 2019), örgütsel adanmışlık (Lee ve diğ., 2014), iş yaşam kalitesi (Kim ve diğ., 2017), iş performansı (Kim ve diğ., 2017), yardım davranışı 
(Supanti ve Butcher, 2019), öznel iyi oluş (Hu ve diğ., 2019), psikolojik intiyaç tatmini (Hu ve diğ., 2019) ve algılanan dışsal prestij (Gürlek ve Tuna, 2019) gibi tutum ve davranışlar üzerine etkili olduğu belirlenmiştir. Yapılan bu araştırmalar, işletmelerin mevcut çalışanları nezdinde KSS faaliyetlerini gerçekleştirerek stratejik önemli çıktılar elde edebileceğini göstermektedir.

\section{Yöntem}

\subsection{Bibliyometrik Analiz}

Bibliyometrik analiz, temel düzeyde ve gelişmiş istatistiksel teknikler kullanarak yayınlanmış bilimsel çalışmaların atıf, yazar künyeleri, anahtar kelimeler, çalışılan konular ve uygulanan metotlar gibi kıstaslara bağlı olarak ilgili disiplindeki gelişimi gözlemlemek ve değerlendirmek için kullanılan bir tekniktir (McBurney ve Novak, 2002). Bir diğer ifadeyle, bibliyometrik analiz, belirli bir konu, disiplin veya sektördeki ilerlemeyi, gelişim veya büyümeyi ölçmek için kullanılan istatistiksel bir tekniktir (Bouyssou ve Marchant, 2011). Bibliyometrik analiz, turizm ve ağırlama yazınında hem ulusal (Boğan ve diğ., 2018b; Çelik, 2019) hem de uluslararası (Köseoğlu ve diğ., 2016; Okumuş ve diğ., 2018; Okumuş ve diğ., 2019) düzeyde sıkça kullanılmaktadır.

\subsection{Dergilerin Seçimi}

Çalışma kapsamına giren dergiler SCIMAGO Institutions Ranking adlı kaynaktan elde edilmiştir. Dergilerin seçiminde iki metot uygulanmıştır. İlk olarak, konu kategorisi kısmından 'turizm, boş zaman ve turizm işletmeciliği' seçeneği seçilmiştir. Bu kapsama giren 107 akademik dergi olduğu belirlenmiştir. Bu dergiler arasında en yüksek etki faktörüne sahip dergiler Q1 kodu ile belirtilmiştir. Çalışmada Q1 kodlu yüksek etki faktörüne sahip dergiler seçilmiştir. Q1 koduna sahip, 25 adet derginin olduğu belirlenmiştir. Bu dergiler arasında sadece KSS ve çalışan tutum ve davranışları arasındaki ilişkiyi inceleyen çalışmaların yayınlandığı dergiler ele alınmıştır. Bu kapsama giren 8 derginin olduğu belirlenmiştir. İkincisi, Q2 koduna sahip olmasına rağmen SSCI indeksinde yer alan Asia Pacific Journal of Tourism Research dergisi konuya ilişkin makaleleri yayınlanmasından dolayı araştırma kapsamına dâhil edilmiştir. Q2 kodlu SSCI indeksinde yer alan diğer dergiler incelendiğinde araştırma kapsamına girebilecek makalenin olmadığı belirlenmiştir. Sonuç olarak, çalışma kapsamına dâhil edilen toplamda 9 akademik derginin adı aşağıda yer almaktadır.

- Asia Pacific Journal of Tourism Research

- Current Issues in Tourism

- Journal of Hospitality and Tourism Management

- Journal of Sustainable Tourism

- Tourism Management

- Tourism Management Perspectives

- Cornell Hospitality Quarterly

- International Journal of Contemporary Hospitality Management

- International Journal of Hospitality Management

\subsection{Veri Toplama ve Analiz}

Seçilen dergilerden çalışma kapsamına giren makaleleri çıkarmak için 'Web of science' sitesinden faydalanılmıştır. Çalışmada araştırmanın kapsamını daraltma adına sadece nicel analiz tekniklerini kullanan çalışmalar incelenmiştir. Yıl olarak herhangi bir kısıtlamaya gidilmemiştir. Arama yaparken 'corporate social responsibility, corporate 
citizenship, corporate responsibility' anahtar kelimeleri kullanılmıştır. Veriler, 05.10.2019-20.11-2019 tarihleri arasında toplanmıştır. Toplamda 26 adet akademik makaleye ulaşılmıştır. Her bir makale içerik analizine tabi tutulmuş ve bunun için ayrı bir çalışma tablosu oluşturulmuştur. Çalışmalarda diğer bibliyometrik çalışmalara (ReyMartí ve diğ., 2016; Okumuş ve diğ., 2019) benzer bir şekilde içerik olarak; çalışmaların yıllara göre dağılımı, çalışmaların dergilere göre dağılımı, çalışmaların ülkelere göre dağılımı, çalışmaların alt sektörlere göre dağılımı, çalışmalarda en çok işlenen konular, çalışmalardaki yazar sayısı ve çalışmalarda en çok yararlanılan teoriler esas alınmıştır.

\section{Bulgular}

\section{1. Çalışmaların Yıllara Göre Dağılımı}

Şekil 1, KSS faaliyetlerinin çalışanların tutum ve davranışlarına yönelik etkisini araştıran çalışmaların yıllara göre dağılımını göstermektedir. Konuya olan ilginin 2012 yılında başladığı görülmektedir. O dönemde yavaş yavaş ilgi gören konu 2014 yılında yayınlanan yedi, 2019 yılında yayınlanan on çalışma ile popülerlik kazanmıştır. 2015, 2017 ve 2018 yıllarında yayınlanan çalışma sayısı ikidir. Konunun nicel yöntemlerle araştırımasına ilgi duyan ilk yazarlar Lee ve arkadaşları (2012)'dır. Araştırmacılar, Güney Kore'de faaliyet gösteren yiyecek-içecek sektörü çalışanlarının KSS algısının örgütsel güven ve iş tatmini üzerine etkisini araştırmışlardır. Çalışmada çalışanların KSS algısı Carroll (1979)'un KSS piramidinin basamaklarını oluşturan ekonomik, yasal, etik ve gönüllü sorumluluk boyutları ile ölçülmüştür.

\section{Şekil 1: Çalışmaların Yıllara Göre Dağılımı}

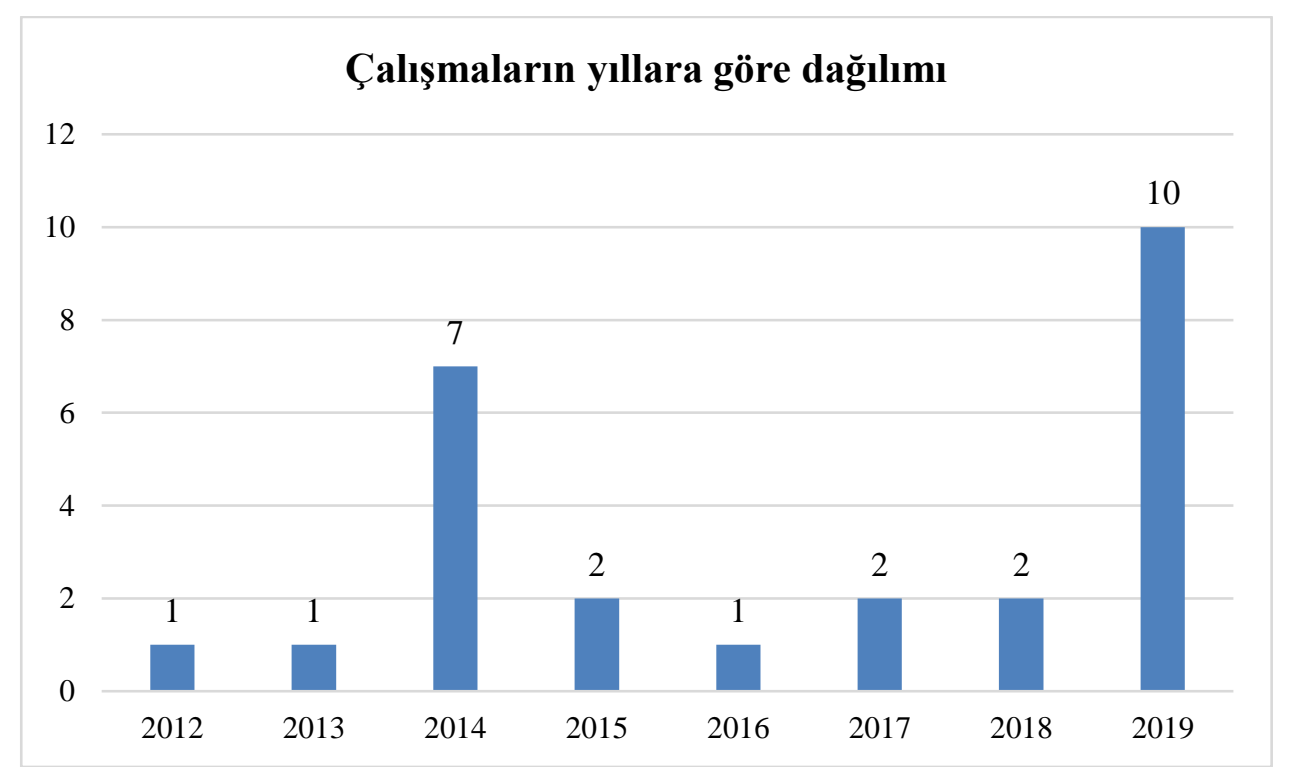

\section{2. Çalışmaların Dergilere Göre Dağılımı}

Şekil 2, yayınlanan yirmi altı çalışmanın dergilere göre dağılımını göstermektedir. Dergilerin beş tanesi turizm dergisi iken, dört tanesi ağırlama işletmeciliği dergisidir. İlgili konuya dair çalışmalar en çok International Journal of Contemporary Hospitality Management (IJCHM) ve International Journal of Hospitality Management (IJHM) dergilerinde yayınlanmıştır. 


\section{Şekil 2: Çalışmaların Akademik Dergilere Göre Dağılımı}

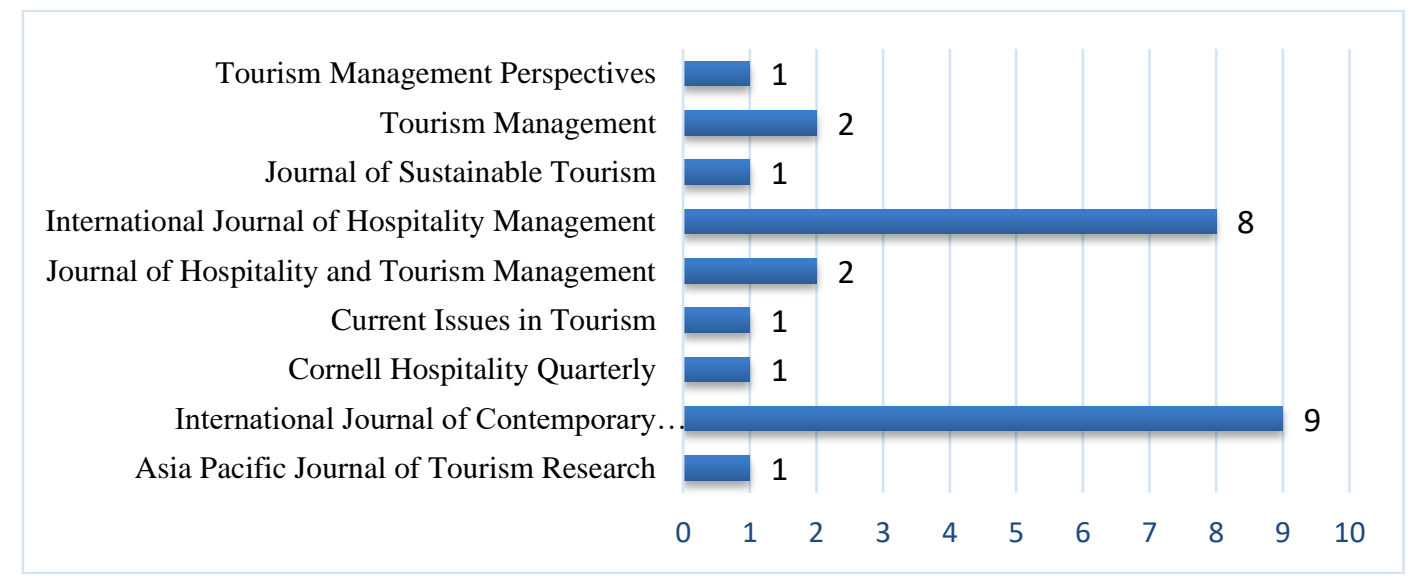

\section{3. Çalışmaların Ülkelere Göre Dağılımı}

Şekil 3, KSS faaliyetlerine çalışanların verdikleri reaksiyonları araştıran çalışmaların gerçekleştirildiği ülkelere göre dağılımını göstermektedir. Çalışmaların çok büyük bir kısmı Çin ve Güney Kore'de gerçekleştirilmiştir. Yine çalışmaların çok büyük bir kısmının Asya kıtasında gerçekleştirildiği görülmektedir. Çalışmalar Avrupa kıtasında sadece Türkiye, Polonya ve Birleşik Krallık'ta gerçekleştirilmiştir. Amerika'da yapılan çalışma sayısı sadece ikidir.

\section{Şekil 3: Çalışmaların Ülkelere Göre Dağılımı}

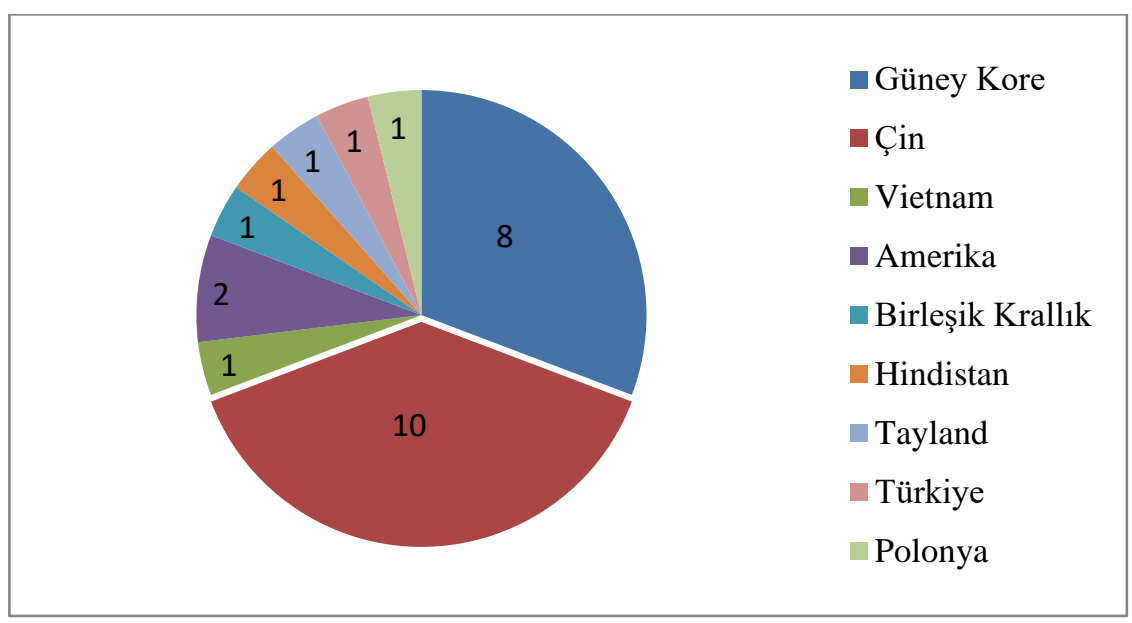

\section{4. Çalışmaların Alt Sektörlere Göre Dağılımı}

Şekil 4, çalışmaların turizm ve ağırlama sektöründe yer alan alt sektörlere göre dağılımını göstermektedir. Bu kapsamda, en fazla çalışmanın otel ve kumarhanelerde gerçekleştirildiği görülmektedir. Kumarhanelerde gerçekleştirilen çalışmaların tamamı Güney Kore'de yapılmıştır. 
Şekil 4: Çalışmaların Alt Sektörlere Dağılımı

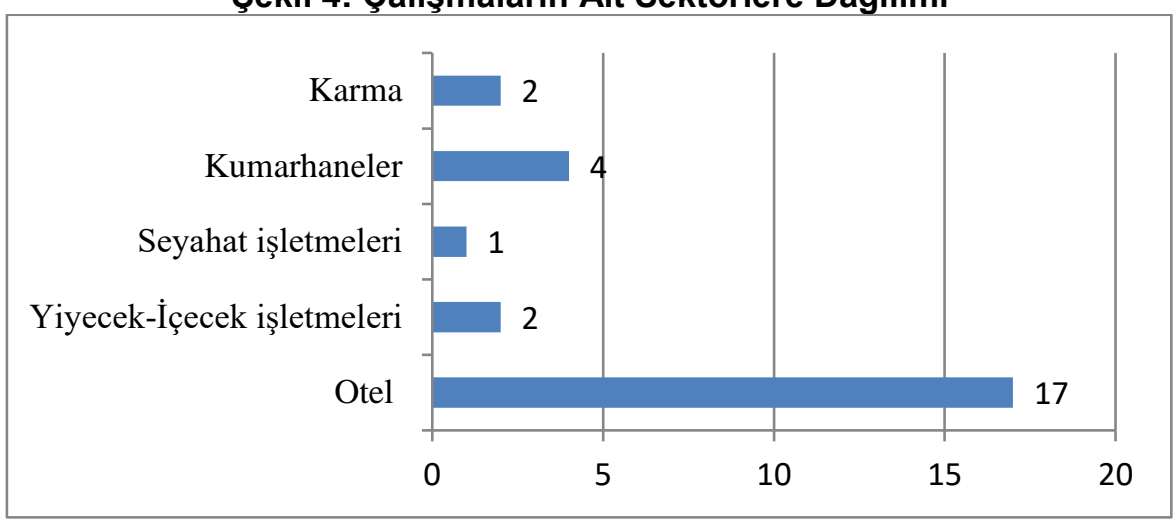

\section{5. Çalışmalarda En Çok İşlenen Konular}

Şekil 5’te çalışanların KSS verdikleri tepkilerde en çok işlenen konular yer almaktadır. Çalışanların KSS algısının üzerine etkisi birden fazla araştırılan kavramlar sırasıyla duygusal bağlılık, iş tatmini, örgütsel özdeşleşme, örgütsel güven, örgütsel vatandaşlık davranışı (ÖVD), işe adanmışlık, örgütsel bağlııı, çevresel anlamda ÖVD, yapılan işin algılanan önemi, işten ayrılma niyeti ve öznel iyi oluştur. Şekilde dikkat çeken önemli hususlardan birisi içerisinde birden fazla boyutu içeren değişkenlerin boyutsal olarak incelenmesidir. Örgütsel bağlılığın önemli boyutlarından biri olan duygusal bağlılık buna bir örnektir.

\section{Şekil 5: Çalışmalarda İşlenen Değişkenlerin Dağılımı}

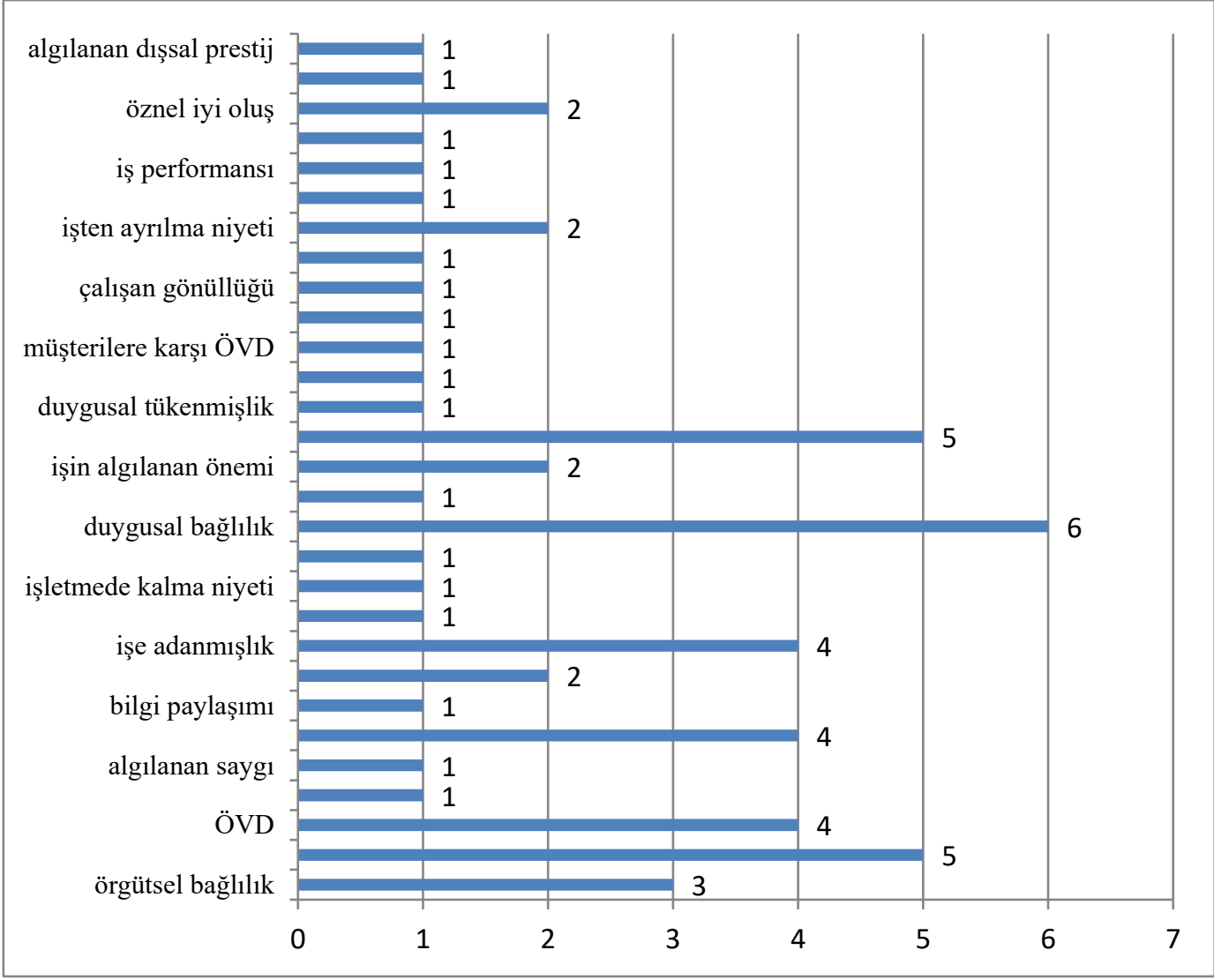




\section{6. Çalışmalardaki Yazar Sayısı}

Şekil 6'da akademik çalışmalardaki yazar sayısı yer almaktadır. Buna göre, en fazla sırasıyla iki yazarlı, dört yazarlı, üç yazarlı, tek yazarlı ve beş yazarlı çalışmalar gerçekleştirilmiştir.

Şekil 6: Çalışmalardaki Yazar Sayısı

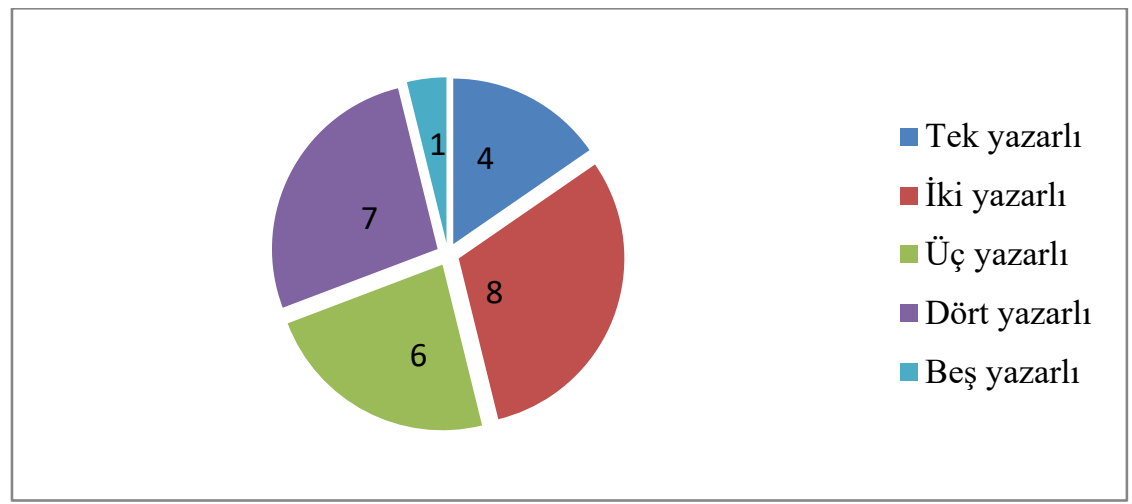

\section{7. Çalışmalarda Faydalanılan Teoriler}

Şekil 7'de çalışmalarda kurulan modele teorik altyapı oluşturma adına yararlanılan teoriler yer almaktadır. Bu kapsamda, en fazla yararlanılan teori sosyal kimlik teorisidir. $\mathrm{Bu}$ teoriyi, sosyal mübadele teorisi, paydaş teorisi ve öz-belirleme teorisi takip etmektedir. Şekilde yer alan diğer ilgili teorilerden sadece birer çalışmada faydalanılmıştır. Ancak şekilde görüldüğü üzere beş çalışmada kurulan model herhangi bir teoriye dayandırılmamıştır. Bu durum, teorik anlamda yeterli altyapı oluşturulmadan çalışmaların gerçekleştirildiğini göstermektedir.

\section{Şekil 7: Çalışmalarda Faydalanılan Teoriler}

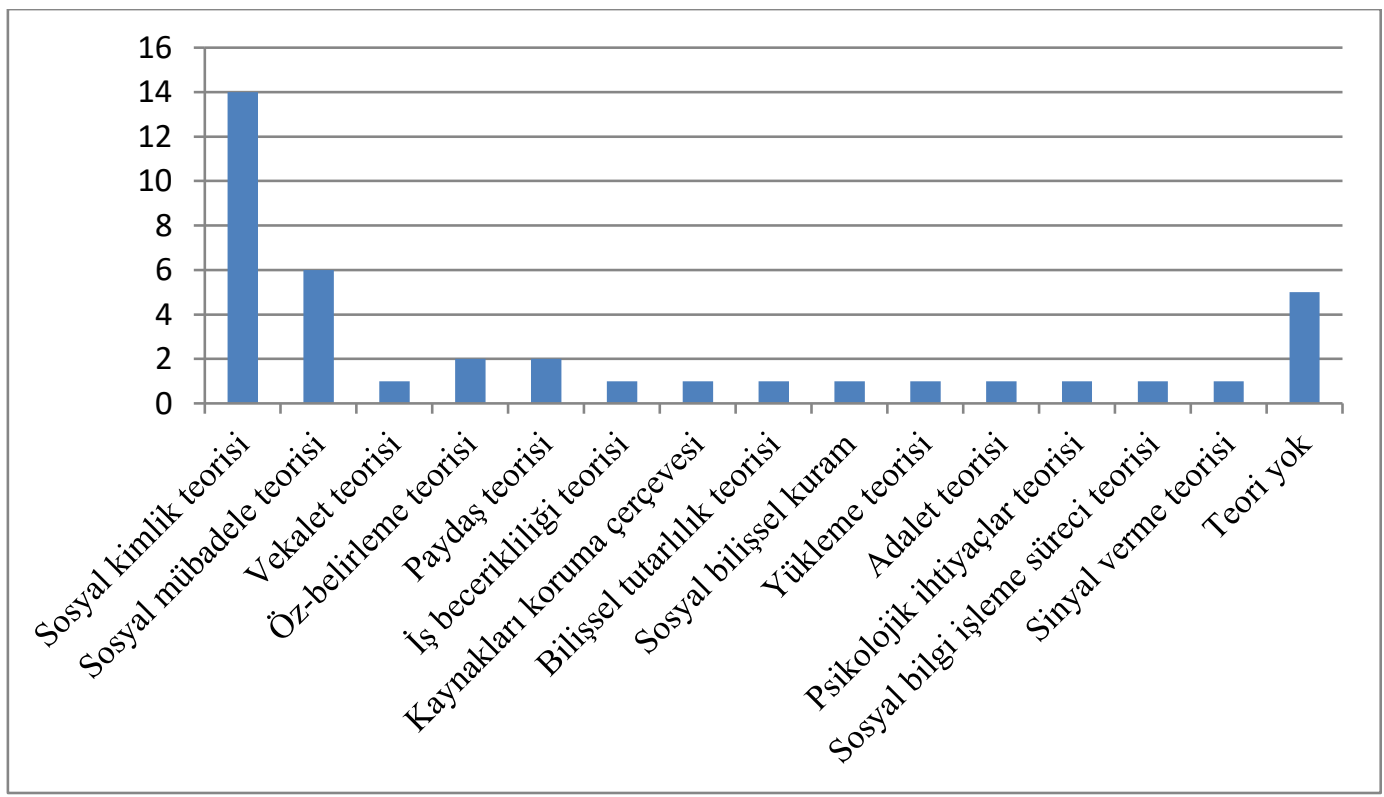




\section{Tartışma}

Turizm ve ağırlama sektöründe mevcut çalışanların KSS faaliyetlerine verdikleri tepkileri araştıran çalışmalara dair bibliyometrik bir makale olan mevcut çalışmadan elde edilen bulgular önemli birtakım sonuçlar ortaya koymaktadır. İlk olarak, 2012 yılına kadar konunun yüksek etki faktörüne sahip herhangi bir dergide yer almadığı görülmektedir. Bu durum aslında konunun henüz yeni popülerlik kazandığını göstermektedir. Yapılan çalışmalar incelendiğinde, ilk dönemlerde çoğunlukla çalışanların KSS algısının tutum ve davranışlarına doğrudan etkisi araştırıırken (Lee ve diğ., 2012; 2013; Park ve Levy, 2014), daha sonraları aracılık rolü üstlenen (Fu ve diğ., 2014a; He ve diğ., 2019) ya da ilişkinin gücünü ya da yönünü farklılaştıran değişkenlerin (Supanti ve Butcher, 2019; Jia ve diğ., 2019) keşfedilmeye çalışıldığı görülmektedir.

İkincisi, yapılan araştırmaların çoğunlukla Asya ülkelerinde gerçekleştirildiği görülmektedir. Yönetim literatüründe çoğunlukla çalışanların KSS faaliyetlerine verdikleri tepkileri ölçen çalışmaların Batılı gelişmiş ülkelerde gerçekleştirildiği görülmektedir. Gelişmekte olan ülkelerde konunun araştırılması tavsiye edilmesine rağmen (Aguinis ve Glavas, 2012), turizm ve ağırlama literatüründe durumun tam tersi olduğunu söylemek mümkündür. Bir diğer ifadeyle, var olan çalışmaların çoğunlukla gelişmekte olan Asya ülkelerinde gerçekleştirildiği dolayısıyla gelişmiş Batılı ülkelerde çalışmaların kısıtlı olduğu ifade edilebilir.

Üçüncüsü, çalışmaların alt sektörlere dağılımları incelendiğinde seyahat ve yiyecek-içecek alt sektörlerinde konuya dair çalışma sayısının oldukça kısıtlı olduğu görülmektedir. KSS faaliyetlerinin çoğunlukla lüks ve büyük ölçekli işletmeler tarafından gerçekleştirildiği göz önüne alındığında, çalışmaların büyük bir kısmının otelcilik sektöründe gerçekleştirilmiş olması makul karşılanabilir. Özellikle Hilton, Wyndam, Accor gibi uluslararası otel zincirleri her yıl toplumun yaşam kalitesini iyileştirme ve doğal çevreyi korumaya dair gerçekleştirdikleri sorumlu girişimleri raporlayarak paydaşlarına iletmektedir. Ancak McDonalds, Burger King, KFC gibi uluslararası fast-food zincirlerinin de kurumsal web sayfalarında paylaştıkları sorumlu girişimler göz önüne alındığında, konunun yiyecek-içecek sektöründe de çalışılması gerektiği ortaya çıkmaktadır.

Dördüncüsü, çalışanların KSS algısının üzerine etkisi en çok araştırılan kavramların; iş tatmini, duygusal bağlılık ve örgütsel özdeşleşme olduğu görülmektedir. $\mathrm{Bu}$ kavramların son araştırmalarda artık nihai bağımsız değişken olarak değil aracı değişken olarak incelendiği göze çarpmaktadır. Örneğin; He ve arkadaşları (2019) KSS ve örgütsel vatandaşlık davranışı ile KSS ve görev performansı arasındaki ilişkide örgütsel özdeşleşmenin aracılık rolünü incelemişlerdir. Kim ve arkadaşları (2016) çalışanların KSS algısının işten ayrılma niyeti üzerine etkisinde duygusal bağlılığın aracılık rolüne sahip olduğunu belirlemiştir. Youn ve arkadaşları (2018) KSS algısının duygusal bağlılık üzerine etkisinde iş tatmininin aracılık rolü üstlendiğini ortaya koymuşlardır.

Son olarak, çalışanların KSS algısının tutum ve davranışlarına olan etkisini inceleyen araştırmacılar kurdukları modele teorik altyapı oluştururken çoğunlukla sosyal kimlik teorisi (Ashforth ve Mael, 1989) ve sosyal mübadele teorisinden (Blau, 1964) faydalanmışlardır. Sosyal kimlik teorisine göre (Ashforth ve Mael, 1989), insanlar doğuştan kendilerini ve başkalarını birtakım sınıflara ya da kategorilere ayırmaktadırlar. Bu sınıflar ya da kategoriler, bireyin benlik kavramının gelişimi ya da korunmasında kalkan rolü üstlenmektedir. Ayrıca bu kategoriler, bireyin sosyal çevrede kendisini ve başkalarını konumlandırmasına yardımcı olmaktadır. Genel olarak sosyal ve çevresel anlamda sorumlu davranışlar sergileyen işletmelerin kurumsal anlamda itibarının yüksek 
olduğu açıktır. Böyle yüksek itibarlı bir işletmede çalışmak, bu işletmenin bir parçası olmak, çalışanın kendini sosyal çevresinde iyi bir yerde konumlandırmasına katkı sağlamaktadır. Bir diğer teori sosyal mübadele teorisidir (Blau, 1964). Bu teorinin en temel prensiplerinden biri mütekabiliyettir. Mütekabiliyet doğrudan ve genelleştirilmiş olarak ikiye ayrılmaktadır. Doğrudan mütekabiliyette, bir taraf diğer tarafa fayda sağlayacak bir eylemde bulunduğunda, fayda elde eden kişi bu eyleme mütekabil fayda sağlayacak bir geri dönüş yapar. Genelleştirilmiş mütekabiliyette ise ikiden fazla taraf bulunmaktadır. Buna göre, her taraf bir başkasına fayda sağlamakta ve fayda sağladığı taraftan olmayacak şekilde fayda elde etmektedir. Bu temel prensiplere bağlı olarak, işletmeler çalışanların kendisine ya da dış paydaşlarına fayda sağlayacak eylemlerde bulunduğunda, çalışanlar kendisi fayda elde etmiyor olsa dahi, bu eyleme mütekabil faydalı geri dönüşlerde bulunacaktır (Cropanzano ve Mitchell, 2005; Molm ve diğ., 2007).

\section{Sonuç}

Bu çalışma, turizm ve ağırlama sektöründe çalışanların KSS faaliyetlerine verdikleri tepkileri inceleyen çalışmalar hakkında yapılmış bibliyometrik bir araştırmadır. Bu kapsamda çalışmaların yıllara, dergilere, ülkelere, alt sektörlere göre dağılımının yanı sıra çalışmalarda en çok işlenen konular, yazar sayısı ve faydalanılan teoriler gibi ölçütler esas alınmıştır. Bilindiği kadarıyla, bu çalışma turizm ve ağırlama sektör çalışanlarının KSS faaliyetlerine verdikleri geri dönüşler hakkında yapılan çalışmaları bibliyometrik analiz ile inceleyen ilk çalışmadır. Çalışma kapsamına yüksek etki faktörüne sahip Q1 kodlu turizm ve ağırlama dergileri dahil edilmiştir. Ek olarak, Q1 koduna sahip olmayan ancak SSCI indeksinde yer alan Asia Pacific Journal of Tourism Research dergisi de kapsama dahil edilmiştir. Ancak yapılan araştırmalar neticesinde 2019 yılı da dahil çalışma kapsamına giren akademik çalışma sayısının sadece yirmi altı olduğu belirlenmiştir. Elde edilen bulgular, araştırmacılara var olan bilgilere dair genel bir bakış sunmaktadır. Aynı zamanda bulgular, araştırmacılar için literatürde ve uygulamada var olan açıklıklara dair önemli ipuçları sunmaktadır.

\subsection{Kısıtlılıklar ve Araştırmacılara Öneriler}

Tıpkı diğer çalışmalarda olduğu gibi, mevcut araştırmada birtakım kısıtılıklara sahiptir. İlk olarak, çalışmada sadece yüksek etki faktörüne sahip $\mathrm{SSCl}$ indeksinde taranan dergilerde yer alan çalışmalar incelenmiştir. Sonraki araştırmalarda, SCIMAGO Institutions Ranking adlı internet kaynağında yer alan diğer turizm ve ağırlama dergilerinde yer alan çalışmalar da bu kapsama dahil edilebilir. Böylece mevcut çalışmadan elde edilen bulgular güçlendirilebilir. İkincisi, çalışmada sadece nicel analiz teknikleri ile gerçekleştirilen çalışmalar incelenmiştir. Sonraki araştırmalarda, nitel yöntemlerle gerçekleştirilen çalışmalar da kapsama dahil edilebilir. Mevcut çalışmadan elde edilen bulgular da aslında araştırmacılara birçok yeni çalışma konusu sunmaktadır. Öncelikle, çalışanların KSS faaliyetlerine verdikleri tepkilerle alakalı çalışma kapsamına dahil edilen dergilerde Türkiye ile ilgili yeterince çalışmanın yapılmadığı görülmektedir. Konunun Türkiye gibi gelişmekte olan bir ülkede araştırılması ilgili literatüre katkı sağlayacaktır. Ayrıca çalışmanın turizm ve ağırlama endüstrisinde farklı alt sektörlerde de (yiyecek-içecek, ulaştırma sektörü) araştırılması ilgili yazına farklı bir bakış getirecektir.

\section{Kaynakça}

Aguinis, H. ve Glavas, A. (2012), 'What We Know and Don't Know about Corporate Social Responsibility: A Review and Research Agenda', Journal of Management, 38(4), ss. 932-968. 
Appiah, J. K. (2019), 'Community-based Corporate Social Responsibility Activities and Employee Job Satisfaction in the US Hotel Industry: An Explanatory Study', Journal of Hospitality and Tourism Management, 38, ss. 140-148.

Ashforth, B. E. ve Mael, F. (1989), 'Social Identity Theory and The Organization', Academy of Management Review, 14(1), ss. 20-39.

Avrupa Birliği Komisyonu (The European Union Commission) (2001). Promoting a European framework for corporate social responsibility. Green Paper of the European Commission. COM (2001) 366, July. Brussels: The EU Commission.

Bavik, A. (2019), 'Corporate Social Responsibility and Service-Oriented Citizenship Behavior: A Test of Dual Explanatory Paths', International Journal of Hospitality Management, 80, ss. 173-182.

Blau, P. M. (1964), Exchange and Power in Social Life. New York: John Wiley.

Boğan, E. ve Dedeoğlu, B. B. (2019a), 'The Effects of Hotel Employees' CSR Perceptions on Trust in Organization: Moderating Role of Employees' SelfExperienced CSR Perceptions', Journal of Hospitality and Tourism Insights, 2(4), ss. 391-408.

Boğan, E. ve Dedeoğlu, B. B. (2019b), 'The Influence of Corporate Social Responsibility in Hospitality Establishments on Students' Level of Commitment and Intention to Recommend', Journal of Hospitality, Leisure, Sport \& Tourism Education, 25, 100205.

Boğan, E., Çalışkan, C. ve Dedeoğlu, B. B. (2018b), 'Turizm Yazınında Kurumsal Sosyal Sorumluluk: Türkiye'de Yapılan Çalışmaların Bibliyometrik Analizi', Turizm Akademik Dergisi, 5(2), ss. 47-62.

Boğan, E., Türkay, O. ve Dedeoğlu, B. B. (2018a), 'Perceived Corporate Social Responsibility and Job Satisfaction: The Mediator Role of Organizational Identification', International Journal of Business and Management Studies, 10(2), ss. 51-67.

Bouyssou, D. ve Marchant, T. (2011), 'Ranking Scientists and Departments in a Consistent Manner', Journal of the American Society for Information Science and Technology, 62(9), ss. 1761-1769.

Bowen, H. R. (1953), Social Responsibilities of Businessman, New York: Harper and Row.

Carroll, A. B. (1979), 'A Three-dimensional Conceptual Model of Corporate Performance', Academy of Management Review, 4(4), ss. 497-505.

Carroll, A. B. (1989), Business and Society: Ethics and Stakeholder Management, 2. Baskı, South-Western Publishing Co. USA, Ohio.

Carroll, A. B. (1991), 'The Pyramid of Corporate Social Responsibility: Toward the Moral Management of Organizational Stakeholders', Business Horizons, 34(4), ss. 3948.

Carroll, A. B. (1999), 'Corporate Social Responsibility: Evolution of a Definitional Construct', Business and Society, 38(3), ss. 268-295.

Coles, T., Fenclova, E. ve Dinan, C. (2013), 'Tourism and Corporate Social Responsibility: A Critical Review and Research Agenda', Tourism Management Perspectives, 6, ss. 122-141.

Cowper-Smith, A. ve de Grosbois, D. (2011), 'The Adoption of Corporate Social Responsibility Practices in the Airline Industry', Journal of Sustainable Tourism, 19(1), ss. 59-77.

Cropanzano, R. ve Mitchell, M. S. (2005), 'Social Exchange Theory: An Interdisciplinary Review', Journal of Management, 31(6), ss. 874-900.

Çelik, S. (2019), 'Turizm Alanında Liderlik Konusu ile İlgili Hazırlanmış Tezlere Yönelik Bibliyometrik Bir Analiz', Journal of Academic Value Studies, 5(4), ss. 516-527. 
Fatma, M., Rahman, Z. ve Khan, I. (2016), 'Measuring Consumer Perception of CSR in Tourism Industry: Scale Development and Validation', Journal of Hospitality and Tourism Management, 27, ss. 39-48.

Fu, H., Li, Y. ve Duan, Y. (2014b), 'Does Employee-perceived Reputation Contribute to Citizenship Behavior? The Mediating Role of Organizational Commitment', International Journal of Contemporary Hospitality Management, 26(4), ss. 593609.

$\mathrm{Fu}, \mathrm{H}$., Ye, B. H. ve Law, R. (2014a), 'You do well and I do well? The Behavioral Consequences of Corporate Social Responsibility', International Journal of Hospitality Management, 40, ss. 62-70.

García de Leaniz, P. M. ve Rodríguez Del Bosque Rodríguez, I. (2015), 'Exploring The Antecedents of Hotel Customer Loyalty: A Social Identity Perspective', Journal of Hospitality Marketing \& Management, 24(1), ss. 1-23.

Gursoy, D., Boğan, E., Dedeoğlu, B. B. ve Çalışkan, C. (2019), 'Residents' perceptions of Hotels' Corporate Social Responsibility Initiatives and its Impact on Residents' Sentiments to Community and Support for Additional Tourism Development', Journal of Hospitality and Tourism Management, 39, ss. 117-128.

Gürlek, M., Düzgün, E. ve Meydan Uygur, S. (2017), 'How Does Corporate Social Responsibility Create Customer Loyalty? The Role of Corporate Image', Social Responsibility Journal, 13(3), ss. 409-427.

Gürlek, M., ve Tuna, M. (2019), 'Corporate Social Responsibility and Work Engagement: Evidence from the Hotel Industry', Tourism Management Perspectives, 31, ss. 195-208.

He, J., Zhang, H. ve Morrison, A. M. (2019), 'The Impacts of Corporate Social Responsibility on Organization Citizenship Behavior and Task Performance in Hospitality: A Sequential Mediation Model', International Journal of Contemporary Hospitality Management, 31(6), ss. 2582-2598.

Hu, B., Liu, J. ve Qu, H. (2019), 'The Employee-focused Outcomes of CSR Participation: The Mediating Role of Psychological Needs Satisfaction', Journal of Hospitality and Tourism Management, 41, ss. 129-137.

Jia, X., Liao, S., Van der Heijden, B. I. ve Guo, Z. (2019), 'The Effect of Socially Responsible Human Resource Management (SRHRM) on Frontline Employees' Knowledge Sharing', International Journal of Contemporary Hospitality Management, 31(9), ss. 3646-3663.

Jiang, Y. ve Gao, Y. (2019), 'Factors That Influence Potential Green Hotel Customers' Decision-Making Process-evidence from China', Journal of China Tourism Research, ss. 1-23.

Kang, J. W. ve Namkung, Y. (2018), 'The Effect of Corporate Social Responsibility on Brand Equity and the Moderating Role of Ethical Consumerism: The Case of Starbucks', Journal of Hospitality \& Tourism Research, 42(7), ss. 1130-1151.

Kim, H. L., Rhou, Y., Uysal, M. ve Kwon, N. (2017), 'An Examination of the Links between Corporate Social Responsibility (CSR) and its Internal Consequences', International Journal of Hospitality Management, 61, ss. 26-34.

Kim, J. S., Song, H. J. ve Lee, C. K. (2016), 'Effects of Corporate Social Responsibility And Internal Marketing on Organizational Commitment and Turnover Intentions', International Journal of Hospitality Management, 55, ss. 25-32.

Ko, A., Chan, A. ve Wong, S. C. (2019), 'A Scale Development Study of CSR: Hotel Employees' Perceptions', International Journal of Contemporary Hospitality Management, 31(4), ss. 1857-1884.

Korschun, D., Bhattacharya, C. B. ve Swain, S. D. (2014), 'Corporate Social Responsibility, Customer Orientation, and the Job Performance of Frontline Employees', Journal of Marketing, 78(3), ss. 20-37. 
Köseoglu, M. A., Rahimi, R., Okumus, F. ve Liu, J. (2016), 'Bibliometric studies in tourism', Annals of Tourism Research, 61, ss. 180-198.

Lee, C. K., Kim, J. S. ve Kim, J. S. (2018), 'Impact of a Gaming Company's CSR on Residents' Perceived Benefits, Quality of Life, and Support', Tourism Management, 64, ss. 281-290.

Lee, C. K., Song, H. J., Lee, H. M., Lee, S. and Bernhard, B. J. (2013), 'The Impact of CSR on Casino Employees' Organizational Trust, Job Satisfaction, and Customer Orientation: An Empirical Examination of Responsible Gambling Strategies', International Journal of Hospitality Management, 33, ss. 406-415.

Lee, S. ve Park, S. Y. (2009), 'Do socially responsible activities help hotels and casinos achieve their financial goals?', International Journal of Hospitality Management, 28(1), ss. 105-112.

Lee, Y. K., Choi, J., Moon, B. Y. ve Babin, B. J. (2014), 'Codes of Ehics, Corporate Philanthropy, and Employee Responses', International Journal of Hospitality Management, 39, ss. 97-106.

Lee, Y. K., Lee, K. H. ve Li, D. X. (2012), 'The Impact of CSR on Relationship Quality and Relationship Outcomes: A Perspective of Service Employees', International Journal of Hospitality Management, 31(3), ss. 745-756.

Li, Y., Fu, H. ve Huang, S. S. (2015), 'Does Conspicuous Decoration Style Influence Customer's intention to Purchase? The Moderating Effect of CSR Practices', International Journal of Hospitality Management, 51, ss. 19-29.

Luo, J. M. (2018), 'A Measurement Scale of Corporate Social Responsibility in Gambling Industry', Journal of Quality Assurance in Hospitality \& Tourism, 19(4), ss. 460475.

Luu, T. T. (2017), 'CSR and Organizational Citizenship Behavior for the Environment in Hotel Industry: The Moderating Roles of Corporate Entrepreneurship and Employee Attachment Style', International Journal of Contemporary Hospitality Management, 29(11), ss. 2867-2900.

McBurney, M. K. ve Novak, P. L. (2002), 'What is Bibliometrics and Why Should You Care?' In Proceedings. IEEE International Professional Communication Conference (ss. 108-114). IEEE.

Molm, L. D., Collett, J. L. ve Schaefer, D. R. (2007), 'Building Solidarity through Generalized Exchange: A Theory of Reciprocity', American journal of sociology, 113(1), ss. 205-242.

Nazir, O. ve Islam, J. U. (2019), 'Influence of CSR-Specific Activities on Work Engagement and Employees' Innovative Work Behaviour: An Empirical Investigation', Current Issues in Tourism, ss. 1-19.

Okumus, B., Köseoglu, M. A. ve Ma, F. (2018), 'Food and Gastronomy Research in Tourism and Hospitality: A Bibliometric Analysis', International Journal of Hospitality Management, 73, ss. 64-74.

Okumus, F., Köseoglu, M. A., Putra, E. D., Dogan, I. C., ve Yildiz, M. (2019), 'A Bibliometric Analysis of Lodging-Context Research from 1990 to 2016', Journal of Hospitality \& Tourism Research, 43(2), ss. 210-225.

Park, S. Y. ve E. Levy, S. (2014), 'Corporate Social Responsibility: Perspectives of Hotel Frontline Employees', International Journal of Contemporary Hospitality Management, 26(3), ss. 332-348.

Park, S. Y., Lee, C. K., ve Kim, H. (2018), 'The Influence of Corporate Social Responsibility on Travel Company Employees', International Journal of Contemporary Hospitality Management, 30(1), ss. 178-196.

Porter, M. E. ve Kramer, M. R. (2006), 'The Link between Competitive Advantage and Corporate Social Responsibility', Harvard Business Review, 84(12), ss. 78-92. 
Raub, S. ve Blunschi, S. (2014), 'The Power of Meaningful Work: How Awareness of CSR Initiatives Fosters Task Significance and Positive Work Outcomes in Service Employees', Cornell Hospitality Quarterly, 55(1), ss. 10-18.

Rey-Martí, A., Ribeiro-Soriano, D. ve Palacios-Marqués, D. (2016), 'A Bibliometric Analysis of Social Entrepreneurship', Journal of Business Research, 69(5), 16511655.

Rodríguez, F. J. G. ve Cruz, Y. D. M. A. (2007), 'Relation between Social-Environmental Responsibility and Performance in Hotel Firms', International Journal of Hospitality Management, 26(4), ss. 824-839.

Song, H. J., Lee, H. M., Lee, C. K. ve Song, S. J. (2015). 'The Role of CSR and Responsible Gambling in Casino Employees' Organizational Commitment, Job Satisfaction, and Customer Orientation', Asia Pacific Journal of Tourism Research, 20(4), ss. 455-471.

Su, L. ve Swanson, S. R. (2019), 'Perceived Corporate Social Responsibility's Impact on The Well-Being and Supportive Green Behaviors of Hotel Employees: The Mediating Role of The Employee-Corporate Relationship', Tourism Management, 72, ss. 437-450.

Su, L., Huang, S. ve Huang, J. (2018), 'Effects of Destination Social Responsibility And Tourism Impacts on Residents' Support for Tourism and Perceived Quality of Life', Journal of Hospitality \& Tourism Research, 42(7), ss. 1039-1057.

Supanti, D. ve Butcher, K. (2019), 'Is Corporate Social Responsibility (CSR) Participation the Pathway to Foster Meaningful Work and Helping Behavior for Millennials?', International Journal of Hospitality Management, 77, ss. 8-18.

Şentürk, F. K., Boğan, E. ve Bayırlı, M. (2019), 'Etik Liderlik ve Materyalist Eğilimlerin Otel Çalışanlarının Kurumsal Sosyal Sorumluluk Algısına Etkisi: Alanya Örneği', Seyahat ve Otel İşletmeciliği Dergisi, 16(1), ss. 136-153.

Thomas, R., Shaw, G. ve Page, S. J. (2011), 'Understanding Small Firms in Tourism: A Perspective on Research Trends and Challenges', Tourism Management, 32(5), ss. 963-976.

Wang, C. J. (2014), 'Do Ethical and Sustainable Practices Matter? Effects of Corporate Citizenship on Business Performance in the Hospitality Industry', International Journal of Contemporary Hospitality Management, 26(6), ss. 930-947.

Wong, A. I. ve Gao, H.J. (2014), 'Exploring the Direct and Indirect Effects of CSR on Organizational Commitment: The Mediating Role of Corporate Culture', International Journal of Contemporary Hospitality Management, 26(4), ss. 500525.

Yılmazdogan, O. C., Secilmis, C. ve Cicek, D. (2015), 'The Effect of Corporate Social Responsibility (CSR) Perception on Tourism Students' Intention to Work in Sector', Procedia Economics and Finance, 23, ss. 1340-1346.

Youn, H., Lee, K. ve Lee, S. (2018), 'Effects of Corporate Social Responsibility on Employees in the Casino Industry', Tourism Management, 68, ss. 328-335.

Zientara, P., Kujawski, L. ve Bohdanowicz-Godfrey, P. (2015), 'Corporate Social Responsibility and Employee Attitudes: Evidence from a Study of Polish Hotel Employees', Journal of Sustainable Tourism, 23(6), ss. 859-880. 